\title{
Poverty is multidimensional. But what are we going to do about it?
}

\author{
Francisco H. G. Ferreira
}

Published online: 24 August 2011

(C) Springer Science+Business Media, LLC 2011

Since the pioneering works of Bourguignon and Chakravarty [4] and Tsui [8], interest in multidimensional poverty measurement has been growing. A number of indices have been proposed, including the Multidimensional Poverty Index (MPI) of Alkire and Santos [3], which was featured in the UNDP's Human Development Report 2010 [9]. But these new indices have not been welcomed universally: one forceful critique is that multidimensional poverty indices pay insufficient attention to the trade-offsor marginal rates of substitution-between different dimensions of well-being when aggregating across them [7].

Some of the debate between proponents and skeptics of multidimensional poverty measurement was featured in the Forum Section in the last issue of this Journal [2, $6,7]$. Those articles actually suggest strong agreement on at least one basic point: "poverty is multidimensional" ([7], p. 236). As a state, poverty is characterized by multiple deprivations: low consumption and inadequate living standards, but also often poor health, a shortened lifespan, limited access to education, knowledge and information, and powerlessness in various domains. This much seems to be beyond dispute.

The question is what to do about it, in measurement terms. Some, like Bourguignon and Chakravarty [4] and Alkire and Foster [1], have proposed scalar indices that seek to combine, in a single number, information from those various dimensions. Ravallion [7], on the other hand, seems to suggest a 'dashboard approach', whereby

I am grateful to Sabina Alkire, Maria Ana Lugo, Nora Lustig and Martin Ravallion for comments on an earlier version of these comments. All remaining errors are mine. The views expressed here are those of the author. They should not be attributed to the World Bank, its Executive Directors, or the countries they represent.

F. H. G. Ferreira ( $\varangle)$

Development Research Group, The World Bank, Washington, DC, USA

e-mail: fferreira@worldbank.org

F. H. G. Ferreira

Institute for the Study of Labour (IZA), Bonn, Germany 
"we may need to focus our efforts and resources on developing the best possible distinct measures of the various dimensions of poverty [...] aiming for a credible set of 'multiple indices' rather than a single 'multidimensional index"' ([7], p. 13; my emphasis.)

In this short comment, I argue that this (admittedly stylized characterization of the) debate-single index versus a 'dashboard'-is a false dichotomy. Essentially, multidimensional poverty analysis is interesting because the joint distribution of achievements contains more information than the marginal distributions. The dependency structure in a joint distribution-e.g. how closely correlated different achievements (or deprivations) are-can affect how we assess poverty in a society, or compare it across time periods, even given identical margins. A dashboard that reported on poverty indices for each dimension separately would miss this aspect of the joint distribution.

This point was made clearly by Duclos et al. [5]. When comparing the joint distributions of two dimensions of health (nutrition and survival probabilities) in Cameroon and Madagascar, they found that both marginal distributions in Cameroon firstorder dominated the corresponding marginal distributions in Madagascar. But there was no dominance of the joint distribution. In this example, a dashboard approach would conclude that poverty was unambiguously greater in Madagascar, while a truly multidimensional assessment - that took the correlations into account-would conclude that no clear ranking was possible.

This arises because the correlation between the two dimensions may be substantially different in one place than in another, so that the cumulative concentration of deprivations could make "overall" poverty 'worse' in a place that has 'better' marginal distributions. Or, as Duclos et al. put it: "It is possible for a set of univariate analyses done independently for each dimension of well-being to conclude that poverty in $\mathrm{A}$ is lower than poverty in $\mathrm{B}$ while a multivariate analysis concludes the opposite, and vice-versa. The key to these possibilities is the interaction of the various dimensions of well-being in the poverty measure and their correlation in the sampled populations". ([5], p. 945)

The multivariate stochastic dominance techniques proposed by Duclos et al. [5] enable poverty analysts to investigate joint distributions of multiple deprivations without making the specific assumptions about trade-offs that rightly upset Ravallion. And if the correlation between deprivations matters-as surely it must-then this approach must be regarded as superior to the dashboard approach, which considers only the marginal distributions. ${ }^{1}$

Naturally, however, multivariate stochastic dominance yields only a partial ordering across joint distributions. What is one to think of scalar indices, that aggregate information about the multiple deprivations into a single number, thus allowing for complete rankings? Just as in the case of uni-dimensional poverty measurement, it would seem that two extreme positions are untenable. The first would be to say that a particular multidimensional poverty index is the one true measure of poverty. The second would be to argue that any particular index makes some unpalatable

\footnotetext{
${ }^{1}$ An important caveat noted by Ravallion [7] is the case where the best data on two separate dimensions (say, health status and consumption expenditures) are to be found in two different data sets, from which no joint distribution can be constructed. Then, a trade-off between data quality and information on the joint distribution may arise. Such trade-offs must be evaluated on a case-by-case basis.
} 
assumptions, so none is admissible. Just as we all recognize the limitations of the headcount index, but still report it (hopefully alongside other measures and more disaggregated and robust analysis), there will clearly be uses for various indices of multidimensional poverty.

Such indices would be most useful, however, if they relied to the greatest possible extent on (shadow or market) prices to aggregate across different goods and services. Only those aspects of well-being for which there can truly be no sensible estimate of relative prices - such as political and personal freedoms, health and, arguably, education-should be treated as separate dimensions. Although food, cooking utensils, toilets, clothing, vehicles, etc., may well be resources that affect different 'functionings', they are best treated as components of a single dimension of welfarecommand over private goods-whose internal weights are given by relative prices.

Such a "residual" view of multidimensionality-where prices are used to aggregate as many commodities (or 'resources') as possible-contrasts with the more "pervasive" view implicit, for example, in Alkire and Santos [3]. Those authors treat indicators for things like: cooking with wood, charcoal or dung; access to a conventional toilet; and the ownership of radios, TVs, telephones, bicycles or cars, as separate dimensions. Each of their six indicators of living standards is then given a weight of 1/18 (in an index that also contains health and education dimensions). While it is true both that prices may vary across different locations within a country, and that such prices reflect a general equilibrium that is in part determined by the prevailing distribution of income, they are still likely to contain more useful information than arbitrary weights, such as 1/18.

Looking at a few core, truly irreducible, dimensions, and investigating the properties of their joint distribution over the population, by means of both dominance analysis and a plurality of well thought-out indices, is likely to generate real insights about poverty, and perhaps to contribute to the design and targeting of policy actions to reduce it.

\section{References}

1. Alkire, S., Foster, J.: Counting and multidimensional poverty measures. J. Public Econ. 95(7-8), 476-487 (2011)

2. Alkire, S., Foster, J.: Understandings and misunderstandings of multidimensional poverty measurement. J. Econ. Inequal. 9(2), 289-314 (2011)

3. Alkire, S., Santos, M.E.: Acute multidimensional poverty: a new index for developing countries. OPHI Working Paper Series \#38, Oxford University (2010)

4. Bourguignon, F., Chakravarty, S.: The measurement of multidimensional poverty. J. Econ. Inequal. 1(1), 25-49 (2003)

5. Duclos, J.-Y., Sahn, D., Younger, S.: Robust multidimensional poverty comparisons. Econ. J. 116(514), 943-968 (2006)

6. Lustig, N.: Multidimensional indices of achievements and poverty: What do we gain and what do we lose? An introduction to the JOEI Forum on multidimensional poverty. J. Econ. Inequal. 9(2), 227-234 (2011)

7. Ravallion, M.: On multidimensional indices of poverty. J. Econ. Inequal. 9(2), 235-248 (2011)

8. Tsui, K.: Multidimensional poverty indices. Soc. Choice Welf. 19(1), 69-93 (2002)

9. UNDP: Human Development Report 2010: The Real Wealth of Nations: Pathways to Human Development. Macmillan, New York (2010) 